\title{
Interactive comment on "Intercomparison of FY-3 and AIRS Gravity Wave Parameter Extraction Based on Three Methods" by Shujie Chang et al.
}

\section{Anonymous Referee \#2}

Received and published: 10 October 2019

This paper introduced gravity wave extractions from temperature profiles of three measurements, AIRS, GNOS, VASS. Three methods were employed: vertical sliding average, double-filter and single-filter.

Overall, the English in the paper is not accurate and scientific at all, making the review task very difficult. The context does not warrant a publication in AG with little physics or any new insights on gravity waves. The filtering and background removing are very common techniques to analyze GWs in temperature profiles. Unfortunately, I would recommend rejection of this paper.

Some detailed comments:

1. line 24: "the GNOS temperature profile product performs better..." What does "bet- 
ter" mean here? Should be more specific. This problem is all over the paper. Line 25: " the AIRS temperature profile product is better than GNOS".

2. How the weighting function of AIRS impacts the vertical resolution of temperature profiles?

3. Is GNOS radio occultation? If so, would COSMIC a better validation?

Interactive

comment

Interactive comment on Ann. Geophys. Discuss., https://doi.org/10.5194/angeo-2019-130, 2019. 